\title{
Correlation between Clinical Phenotypes and X-inactivation Patterns in Six Female Carriers with Heterozygote Vasopressin Type 2 Receptor Gene Mutations
}

\author{
MARI SATOH*, SAYAKA OGIKUBO*,** AND ATSUKO YOSHIZAWA-OGASAWARA*,** \\ *First Department of Pediatrics, Toho University School of Medicine, Tokyo 143-8541, Japan \\ **Okinaka Memorial Institute for Medical Research, Tokyo 105-8470, Japan
}

\begin{abstract}
About $90 \%$ of patients with congenital nephrogenic diabetes insipidus (NDI) have vasopressin type 2 receptor $(\mathrm{V} 2 \mathrm{R})$ gene mutations that are inherited in an X-linked recessive manner. Although most female carriers are asymptomatic, some female carriers show polydipsia and polyuria. The reason why female carriers show NDI symptoms is explained by skewed X-inactivation. We studied X-inactivation patterns of six female carriers with heterozygote V2R gene mutations. The X-inactivation pattern in peripheral blood leukocytes was examined using methylation analysis of the polymorphic CAG repeat in the androgen receptor gene. Two asymptomatic female carriers showed random Xinactivation $(61.9 \%$ and $60.7 \%)$. Skewed $X$-inactivation patterns $(71.6 \%, 79.4 \%$, and $91.2 \%)$ occurring preferentially to normal $\mathrm{X}$ alleles were recognized in three female carriers who showed clinical NDI symptoms. However, in one female carrier who showed clinical NDI symptoms, random X-inactivation (55.4\%) was recognized. In conclusion, the clinical NDI phenotypes may correlate with the X-inactivation patterns in female carriers with heterozygote V2R gene mutations. However, in some female carriers, we cannot predict the clinical phenotypes by the evaluation of the X-inactivation patterns in peripheral blood leukocytes, because $\mathrm{X}$-inactivation ratios within an individual are sometimes different between tissues.
\end{abstract}

Key words: Nephrogenic diabetes insipidus, Vasopressin receptor, X-inactivation, Female carrier

(Endocrine Journal 55: 277-284, 2008)

\begin{abstract}
ABOUT $90 \%$ of patients with congenital nephrogenic diabetes insipidus (NDI) are males who have mutations of the vasopressin type 2 receptor (V2R) gene [1] on the $\mathrm{X}$ chromosome (Xq28). The remaining 10\% patients have mutations of the aquaporin 2 (AQP2) water channel gene [2] on chromosome 12q13, which are inherited in an autosomal recessive manner. Although most of the female carriers with heterozygote V2R gene mutations are usually asymptomatic, some female carriers have been reported to show polydipsia and polyuria similar to those of male patients [3-7]. The reason why female carriers with heterozygote V2R
\end{abstract}

Received: May 15, 2007

Accepted: November 22, 2007

Correspondence to: Mari SATOH, M.D., First Department of Pediatrics, Toho University School of Medicine, 6-11-1 Oomorinishi, Oota-ku Tokyo 143-8541, Japan gene mutations show NDI symptoms is explained by skewed X-inactivation [5-7]. We studied the correlation between the clinical NDI phenotypes and the Xinactivation patterns in six female carriers with heterozygote $\mathrm{V} 2 \mathrm{R}$ gene mutations.

\section{Subjects and Methods}

Subjects

Family 1

The proband was a 20 year old male. He was initially referred to another hospital because of fever on the $11^{\text {th }}$ day of his life, and was diagnosed as having congenital NDI. When he was six years old, he was brought to our hospital and was reevaluated. At that time, his urine osmolality showed little increase, both 
a

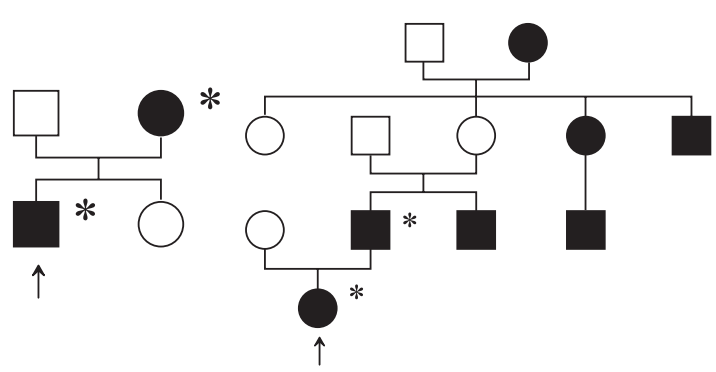

c

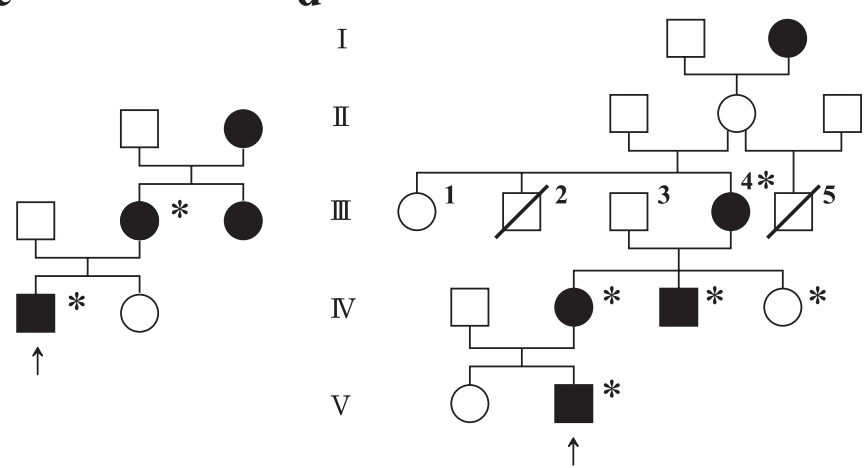

Fig. 1. The family trees of Family 1 (a), Family 2 (b), Family 3 (c) and Family 4 (d). Solid symbols denote the affected individuals. Probands are shown by arrows. Asterisks show the members examined by direct sequencing analysis. In Family 4, III-2 died of diarrhea and dehydration at the age of 4 years old and III-5 died of fever and dehydration during the neonatal period.

after the water deprivation test (before: $75 \mathrm{mOsm} / \mathrm{kg}$, and after: $89 \mathrm{mOsm} / \mathrm{kg}$ ) and after an infusion of $20 \mu \mathrm{g}$ desmopressin acetate (DDAVP) (before: $61 \mathrm{mOsm} / \mathrm{kg}$, and after: $71 \mathrm{mOsm} / \mathrm{kg}$ ). His mother was asymptomatic. The family tree of Family 1 is shown in Fig. 1-a.

\section{Family 2}

The proband was a 9 year old girl. She was referred to our hospital because of polydipsia (3 liters/day; 5 liters $/ \mathrm{m}^{2} /$ day) when she was 3 years old. Since the change in her urine osmolality before and after the water deprivation test was small (before: $86 \mathrm{mOsm} / \mathrm{kg}$, and after: $130 \mathrm{mOsm} / \mathrm{kg}$ ) and the intramuscular infusion of $2 \mathrm{U}$ pitressin did not concentrate her urine osmolality sufficiently (before: $86 \mathrm{mOsm} / \mathrm{kg}$, and after: $216 \mathrm{mOsm} / \mathrm{kg}$ ), she was diagnosed as having congenital NDI. Her father also showed polydipsia (8-9 liters/day) and polyuria. The family tree of Family 2 is shown in Fig. 1-b.

\section{Family 3}

The proband was a 6 year old boy. He received a diaphragmatic relaxation operation on the $5^{\text {th }}$ day of the life. After the operation, hypernatremia (150$160 \mathrm{mM}$ ) was recognized and his plasma arginine vasopressin (AVP) was extremely high $(26.0 \mathrm{pg} / \mathrm{ml})$. Since the infusion of $2.5 \mu \mathrm{g}$ desmopressin acetate (DDAVP) did not increase urine osmolality (before: $60 \mathrm{mOsm} / \mathrm{kg}$, and after: $100 \mathrm{mOsm} / \mathrm{kg}$ ), he was diagnosed as having congenital NDI. His mother also showed polydipsia (4 liters/day) and polyuria. The family tree of family 3 is shown in Fig. 1-c.

\section{Family 4}

The proband was a 1 year old boy. He was referred to the hospital because of fever when he was 1 month old. His serum sodium level was high $(152-166 \mathrm{mM})$ and polyuria $\left(600-900 \mathrm{ml} /\right.$ day: $3-4.5$ liters $/ \mathrm{m}^{2} /$ day) was recognized. Since the infusion of desmopressin acetate (DDAVP) did not increase urine osmolality, he was diagnosed as having congenital NDI. His maternal uncle had been diagnosed as having congenital NDI in infancy. His mother and maternal grandmother also showed polydipsia (3-4 liters/day and 5-6 liters/day, respectively) and polyuria. However, his maternal aunt was asymptomatic. The family tree of Family 4 is shown in Fig. 1-d.

The clinical findings of six female carriers (the mother in Family 1, the proband in Family 2, the mother in Family 3, the mother, the aunt and the grandmother in Family 4) are shown in Table 1.

\section{Methods}

The study was approved by the institutional review board (Toho University School of Medicine), and informed consent to participate in the study was obtained from patients' parents or each subject. Genomic DNA was extracted from peripheral blood leukocytes. All exons of the V2R gene were amplified by polymerase chain reaction (PCR). Primers for amplifying V2R gene are shown in Table 2. The genomic DNA was amplified using two sets of primers (F1-R2, F2-R4). The PCR fragment produced using primer pair F1-R2 was then amplified with nested primer pair F1-R1, and the PCR fragment produced using primer pair F2-R4 
Table 1. Clinical findings of female carriers

\begin{tabular}{cllcc}
\hline Family & Female carrier & \multicolumn{1}{c}{ Water intake } & Plasma osmolality $(\mathrm{mOsm} / \mathrm{kg})$ & Plasma AVP $(\mathrm{pg} / \mathrm{ml})$ \\
\hline 1 & Mother & asymptomatic & ND & ND \\
2 & Proband & 3 liters/day $\left(5\right.$ liters $/ \mathrm{m}^{2} /$ day) & $285^{*}$ & $7.12^{*}$ \\
3 & Mother & 4 liters/day & $286^{* *}$ & $7.05^{* *}$ \\
4 & Mother & $3-4$ liters/day & $286^{* * *}$ & $5.59^{* * *}$ \\
4 & Grandmother & $5-6$ liters/day & $286^{* * *}$ & $8.66^{* * *}$ \\
4 & Aunt & asymptomatic & ND & ND \\
\hline
\end{tabular}

ND: not detected

Blood samplings at the end of the water deprivation test $(*)$, at the end of Fishburg test $(* *)$, and at any time $(* * *)$.

Table 2. Sequence of primers used for PCR and direct sequencing of V2R gene

\begin{tabular}{cll}
\hline & \multicolumn{1}{c}{ sequence of primers } & \multicolumn{1}{c}{ position } \\
\hline F1 & AGAGGCTGAGTCCGCACATC & 5'-untranslated region \\
F2 & TGCTAGGAGCCAGGAAGTGGGTGT & intron 1 \\
F3 & GCTCTCCATAGTCTTTGTGGCTGT & exon 2 \\
F4 & CCTGTGTCGGGCCGTGAAGTA & exon 2 \\
F5 & CGCCTGCCAGGTGCTCATCTT & exon 2 \\
F6 & GTAGCCGTGGCTAGGGCTGACG & intron 2 \\
R1 & AGACGTGTATGGGTGCCCAGTGGC & exon 2 \\
R2 & CACGGTGGCGGTCCAGCGT & exon 2 \\
R3 & TAGGTTGGGTTCAGGATGGCT & intron 2 \\
R4 & GGAGGGATTAGAAAGGCGGAGACA & 3'-untranslated region \\
\hline
\end{tabular}

was amplified with five sets of nested primer pairs (F2-R1, F3-R2, F4-R3, F5-R3, and F6-R4). The PCR conditions were $1 \mathrm{~min}$ at $94^{\circ} \mathrm{C}, 1 \mathrm{~min}$ at $62^{\circ} \mathrm{C}$, and 1 $\min$ at $72^{\circ} \mathrm{C}$ for 35 cycles. Each amplified product was gel purified and sequenced by an automated DNA sequence analyzer (ABI 310 autosequencer, Applied Biosystems, Foster City, CA).

The $\mathrm{X}$-inactivation patterns of female carriers were investigated by studying the polymorphic trinucleotide (CAG) repeat in the first exon of the human androgen receptor gene [8]. First, DNA samples were digested using methylation-sensitive restriction enzymes (HpaII and HhaI) whose cleavage sites were close to the CAG repeat element in the first exon of the androgen receptor gene. Both digested and undigested DNA samples were amplified by PCR method using primers for the androgen receptor locus that included the HpaII and Hhal cleavage sites and the CAG repeat element, as reported in Allen et al. [8]. At that time, the forward primer was modified with fluorescein (6'-FAM) [9]. In digested samples, amplification occurred if the restriction sites were methylated, and amplification did not occur if the restriction sites were not methylated. Next, the PCR products were resolved by electrophoresis, with Rox molecular markers, in an automated sequencer, and peak heights were analyzed using GeneScan software (Applied Biosystems). Peak height ratios for the two alleles in digested samples were corrected using peak height ratios for the two alleles in undigested samples. The ratios of the skewed X-inactivation in digested samples were then calculated by normalizing the sum of the two alleles to $100 \%$.

The $\mathrm{X}$-inactivation pattern was classified as random (allele ratios $50: 50-65: 35$ ), moderately skewed (ratios $65: 35-80: 20$ ), highly skewed (ratios $80: 20$ $90: 10$ ) and extremely skewed (ratios $90: 10-100: 0$ ), following the classification used in previous reports [10].

\section{Results}

Mutation of $V 2 R$ gene

A 468G-A transition, resulting in a trp156-to-ter (W156X) substitution was identified in Family 1. In 


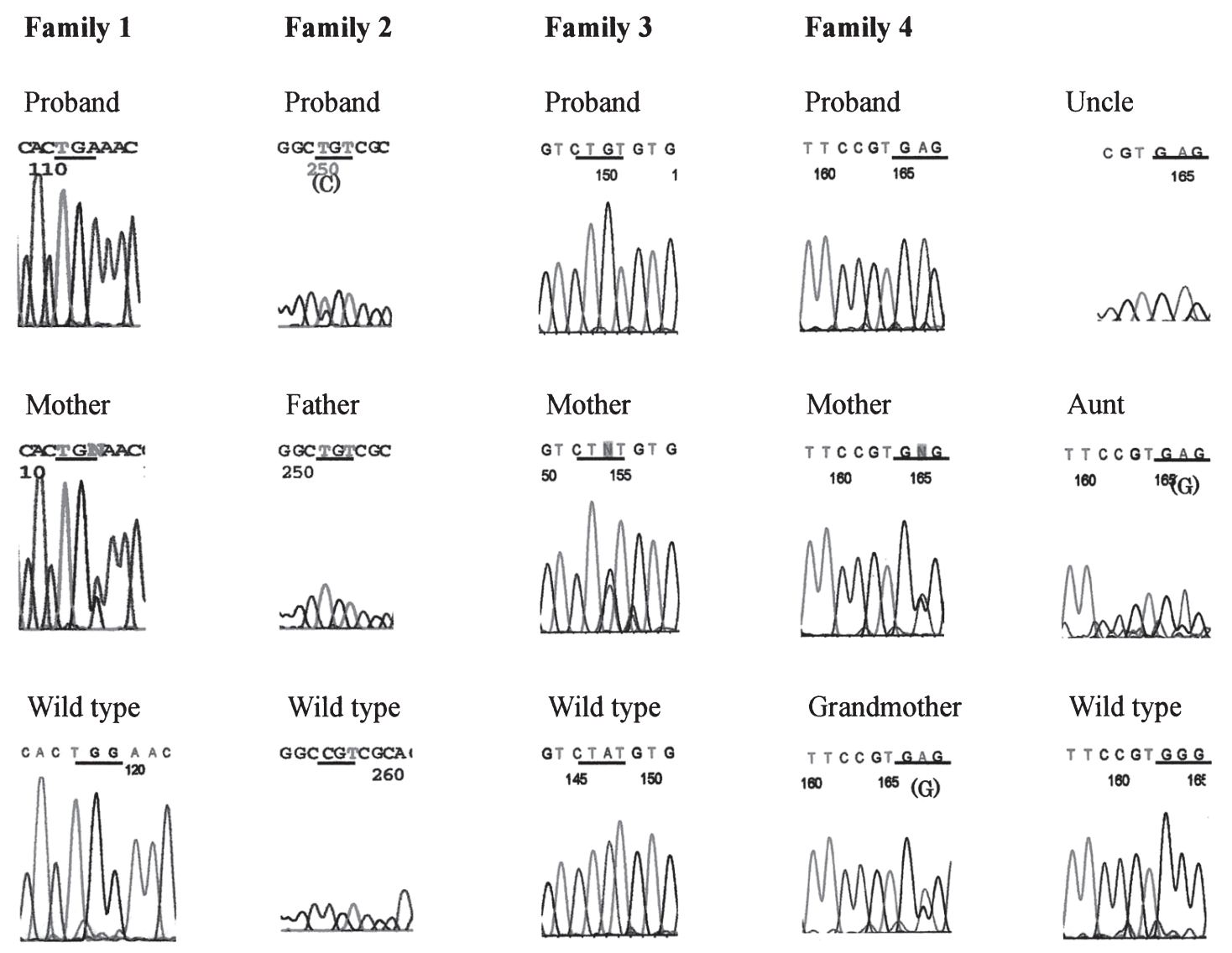

Fig. 2. Sequence analysis of the vasopressin type 2 receptor gene. A 468G-A transition in Family 1, a 604C-T transition in Family 2 , a 839A-G transition in Family 3, and a 320G-A transition in Family 4 are identified. The initial base of the initiation codon is denoted as nucleotide 1 .

Family 2, a 604C-T transition, resulting in an $\arg 202-$ to-cys (R202C) substitution was found. A 839A-G transition, resulting in a tyr280-to-cys (Y280C) substitution were recognized in Family 3. A 320G-A transition, resulting in an gly107-to-glu (G107E) was identified in Family 4. All female carriers had both normal and abnormal alleles (Fig. 2).

\section{Assay for X-inactivation}

The results of GeneScan analysis of the androgen receptor CAG repeat are shown in Fig. 3. Peak height ratios for the two alleles in undigested samples and digested samples are shown in Table 3. The values of relative $\mathrm{X}$-inactivation for normal allele were $38.1 \%$ in the mother of Family 1, 71.6\% in the proband of Family 2, 79.4\% in the mother of Family 3, 44.6\% in the mother of Family 4, 91.2\% in the grandmother of Family 4, and 39.3\% in the aunt of Family 4.

\section{Discussion}

More than 150 kinds of mutations of the V2R gene have been identified to date. The mutations are scattered within the coding region and there is no hot spot. Of the mutations found in this study, only the W156X mutation identified in Family 1 is novel. Mechanism by which female carriers with heterozygote V2R gene mutations show NDI symptoms is explained by Xinactivation occurring preferentially to the normal allele of theV2R gene [5-7]. It has been reported that female carriers who show clinical symptoms similar to those of male patients have skewed X-inactivation in other X-linked recessive disorders, such as Duchenne muscular dystrophy [11], hemophilia B [12], LeschNyhan syndrome [13], ornithine transcarbamylase (OTC) deficiency [14], X-linked myotubular myopathy [15], Fabry disease [16], sideroblastic anemia [17], and Lowe syndrome [18]. 
a

Proband

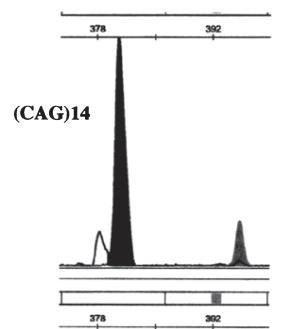

Mother

(Undigested

sample)

(CAG)14

(CAG)16

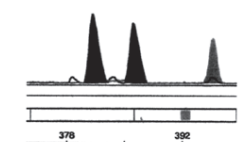

Mother

(Digested

sample)

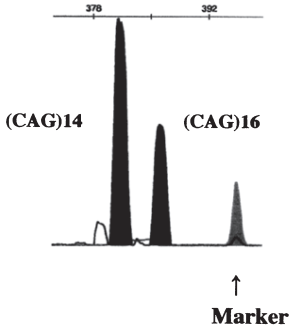

c

Proband

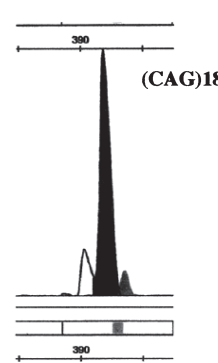

Mother

(Undigested

sample)

(CAG)17

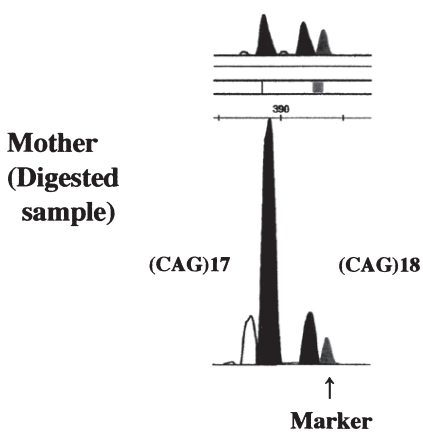

b

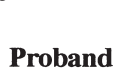

(Undigested

sample)
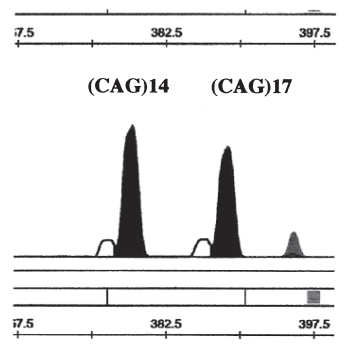

Proband

(Digested

sample)

Father

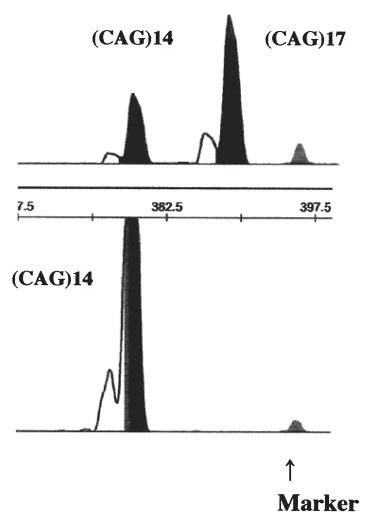

d

Proband

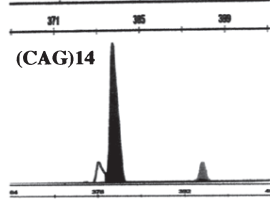

Mother

(Undigested

sample)

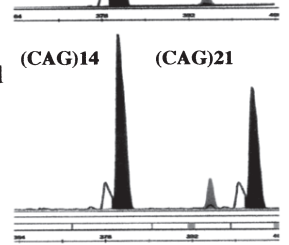

Mother

(Digested

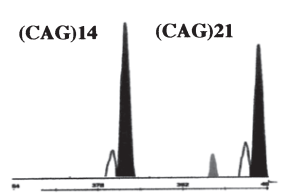

sample)

Grandmothe

Grandmothe
(Undigested

sample)

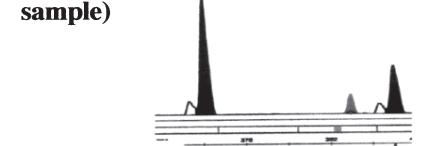

Grandmother

(Digested

sample)

Aunt

(Digested (CAG)11 (CAG)14

sample)

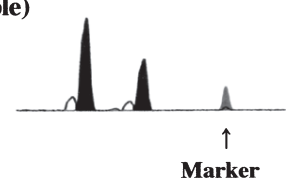

(CA

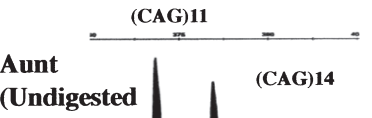

sample)
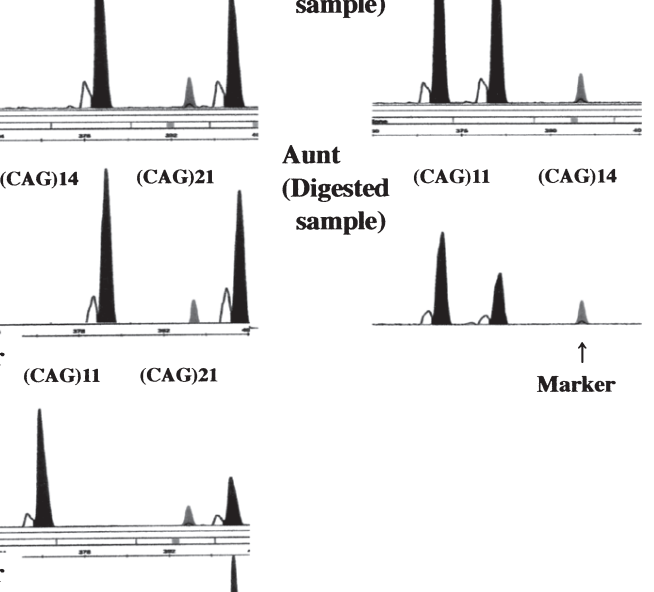

(CAG)11 (CAG)21

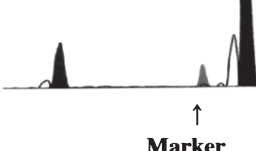

Fig. 3. GeneScan analysis of androgen receptor CAG repeat (a: Family 1, b: Family 2, c: Family 3, d: Family 4). In digested samples of female carriers, amplification occurs if the restriction sites are methylated, and amplification does not occur if the restriction sites are not methylated. 
Table 3. The results of GeneScan analysis

\begin{tabular}{clccc}
\hline \multirow{2}{*}{ Family } & Female carrier & \multicolumn{2}{c}{ Peak height ratio for the two alleles } & $\begin{array}{c}\text { Relative X-inactivation ratio } \\
\text { for normal allele (\%) }\end{array}$ \\
\cline { 3 - 4 } & Mother & \multicolumn{1}{c}{ Undigested sample } & Digested sample & 38.1 \\
\hline 1 & Proband & $(\mathrm{CAG})_{14} /(\mathrm{CAG})_{16}=1.15$ & 1.88 & 71.6 \\
2 & Mother & $(\mathrm{CAG})_{11} /(\mathrm{CAG})_{17}=1.20$ & 0.47 & 79.4 \\
3 & Mother & $(\mathrm{CAG})_{14} /(\mathrm{CAG})_{21}=1.22$ & 4.73 & 44.6 \\
4 & Grandmother & $(\mathrm{CAG})_{11} /(\mathrm{CAG})_{21}=2.46$ & 1.16 & 91.2 \\
4 & Aunt & $(\mathrm{CAG})_{11} /(\mathrm{CAG})_{14}=1.16$ & 0.24 & 39.3 \\
\hline
\end{tabular}

In our study, the normal $\mathrm{X}$ alleles of the asymptomatic mother of Family 1 and the asymptomatic aunt of Family 4 were inactivated $38.1 \%$ and $39.3 \%$ (random $\mathrm{X}$-inactivation). Skewed X-inactivation occurring preferentially to normal $\mathrm{X}$ alleles was recognized in the proband of Family 2 (71.6\%), the mother of Family 3 (79.4\%), and the grandmother of Family 4 (91.2\%) who showed clinical NDI symptoms. The results for these five female carriers suggest that the dominant methylation occurring to the normal allele of the V2R gene causes clinical NDI symptoms of the female carriers as previously reported. However, the degree of skewed $\mathrm{X}$-inactivation in symptomatic female carriers is different between previous reports and our study. In previous reports [5-7], extremely or highly skewed $\mathrm{X}$-inactivation was recognized in four out of five symptomatic female carriers $(94.3 \%, 93 \%, 89 \%$, and $84 \%$ ). On the other hand, two out of three symptomatic female carriers had moderately skewed X-inactivation in our study. Although definitive proof can only be obtained by the analysis of renal tubular cells, moderately skewed X-inactivation may also cause clinical NDI symptoms of female carriers.

In Family 4, the grandmother, who showed severe clinical symptoms, had extremely skewed X-inactivation $(91.2 \%)$. Although the grandmother was supposed to have a normal V2R gene on the same chromosome as the $(\mathrm{CAG})_{21}$ allele and a mutant V2R gene on the same chromosome as the $(\mathrm{CAG})_{11}$ allele, based on the result of GeneScan analysis, the mother had the $(\mathrm{CAG})_{14}$ and the $(\mathrm{CAG})_{21}$ alleles. This suggests that the mutant V2R gene of the grandmother moved to the $(\mathrm{CAG})_{21}$ allele from the $(\mathrm{CAG})_{11}$ allele via meiotic recombination. Moreover, although the mother was supposed to have a mutant $\mathrm{V} 2 \mathrm{R}$ gene on the same chromosome as the $(\mathrm{CAG})_{21}$ allele, the proband had the $(\mathrm{CAG})_{14}$ allele. This phenomenon suggest that the mutant V2R gene of the mother also moved to the
$(\mathrm{CAG})_{14}$ allele from the $(\mathrm{CAG})_{21}$ allele via meiotic recombination.

In the mother of Family 4 who showed moderate NDI phenotype, the $\mathrm{X}$-inactivation ratio observed for the normal $\mathrm{X}$ allele was $44.6 \%$ (random X-inactivation) in peripheral blood leukocytes. Moses et al. [3] reported a female carrier with heterozygote V2R gene mutation who showed half the normal factor VIII response to desmopressin as other asymptomatic female carriers, in spite of showing a total lack of antidiuretic response to desmopressin like that of male NDI patients. They speculated that the $\mathrm{X}$-inactivation ratios were different between the tissues in this female carrier. Sharp et al. [19] reported that although there was a significant correlation of the $\mathrm{X}$-inactivation ratios between each tissue in most individuals, the X-inactivation ratios within an individual varied widely between different cell lineages in some normal females. Therefore, we supposed that X-inactivation ratios may be different between peripheral blood leukocytes and renal tubular cells in the mother of Family 4. In other Xlinked recessive disorders, differences between clinical phenotypes of female carriers and the $\mathrm{X}$-inactivation ratios in peripheral blood were found. Sumita et al. [20] reported that no significant correlation was found between the $\mathrm{X}$-inactivation ratio in blood and serum CK activity in Duchenne/Becker muscular dystrophy carriers. Orstavik et al. [21] reported that the wide range in plasma concentration of factor VIII and IX in haemophilia A and B carriers could not be explained by the $\mathrm{X}$ chromosome inactivation patterns in peripheral blood cells. Yorifuji et al. [14] reported that although the $\mathrm{X}$-inactivation ratio of peripheral blood cells was not correlated with the OTC activity, the X-inactivation ratio of hepatic cells was well correlated with the OTC activity in female manifesting carriers with OTC deficiency.

Since it has been reported that the incidence of ex- 
tremely skewed X-inactivation (ratios $90: 10-100: 0$ ) in peripheral blood is $9-16 \%$ in normal females [19, 22], the extremely skewed X-inactivation is considered not to be a rare phenomenon. Therefore, female carriers with heterozygote V2R gene mutations who show NDI symptoms might be more common than previously reported. We must observe the clinical symptoms of female carriers with heterozygote V2R gene mutations more carefully.
In conclusion, the clinical NDI phenotypes may correlate to the $\mathrm{X}$-inactivation patterns in female carriers with heterozygote V2R gene mutations. However, in some female carriers we cannot predict the clinical phenotypes by the evaluation of the $\mathrm{X}$-inactivation pattern in peripheral blood leukocytes, because X-inactivation ratios within an individual sometimes vary widely between different cell lineages.

\section{References}

1. Birnbaumer $M$, Seibold $A$, Gilbert $S$, Ishido $M$, Barberis C, Antaramian A, Brabet P, Rosenthal W (1992) Molecular cloning of the receptor for human antidiuretic hormone. Nature 357: 333-335.

2. Sasaki S, Fushimi K, Saito H, Saito F, Uchida S, Ishibashi K, Kuwahara M, Ikeuchi T, Inui K, Nakajima K, Watanabe TX, Marumo F (1994) Cloning characterization, and chromosomal mapping of human aquaporin of collecting duct. J Clin Invest 93: 1250-1256.

3. Moses AM, Sangani G, Miller JL (1995) Proposed cause of marked vasopressin resistance in a female with an X-linked recessive V2 receptor abnormality. $J$ Clin Endocrinol Metab 80: 1184-1186.

4. Lieburg AF van, Verdijk MA, Schoute F, Ligtenberg MJ, Oost BA van, Waldhauser F, Dobner M, Monnens LA, Knoers NVAM (1995) Clinical phenotype of nephrogenic diabetes insipidus in females heterozygous for a vasopressin type 2 receptor mutation. Hum Genet 96: 70-78.

5. Nomura $\mathrm{Y}$, Onigata $\mathrm{K}$, Nagashima $\mathrm{T}$, Yutani $\mathrm{S}$, Mochizuki H, Nagashima K, Morikawa A (1997) Detection of skewed X-inactivation in two female carriers of vasopressin type 2 receptor gene mutation. J Clin Endocrinol Metab 82: 3434-3437.

6. Arthus M-F, Lonergan M, Crumley MJ, Naumova AK, Morin D, De Marco L, Kaplan BS, Robertson GL, Sasaki S, Morgan K, Bichet DG, Fujiwara TM (2000) Report of 33 novel AVPR2 mutations and analysis of 117 families with X-linked nephrogenic diabetes insipidus. J Am Soc Nephrol 11: 1044-1054.

7. Kinoshita K, Miura Y, Nagasaki H, Murase T, Bando Y, Oiso Y (2004) A novel deletion mutation in the arginine vasopressin receptor 2 gene and skewed $\mathrm{X}$ chromosome inactivation in a female patient with congenital nephrogenic diabetes insipidus. J Endocrinol Invest 27: 167-170.

8. Allen RC, Zoghbi HY, Moseley AB, Rosenblatt HM, Belmont JW (1992) Methylation of HpaII and HhaI sites near the polymorphic CAG repeat in the human androgen-receptor gene correlates with $\mathrm{X}$ chromosome inactivation. Am J Hum Genet 51: 1229-1239.

9. Pegoraro E, Schimke RN, Arahata K, Hayashi Y, Stern H, Marks H, Glasberg MR, Carroll JE, Taber JW, Wessel HB, Bauserman SC, Marks WA, Toriello HV, Higgins JV, Appleton S, Schwartz L, Garcia CA, Hoffman EP (1994) Detection of new paternal dystrophin gene mutations in isolated cases of dystrophinopathy in females. Am J Med Genet 54: 989-1003.

10. Orstavik KH, Orstavik RE, Eiklid K, Tranebjaerg L (1996) Inheritance of skewed X chromosome inactivation in a large family with an X-linked recessive deafness syndrome. Am J Med Genet 64: 31-34.

11. Yoshioka M, Yorifuji T, Mitsuyoshi I (1998) Skewed $\mathrm{X}$ inactivation in manifesting carriers of Duchenne muscular dystrophy. Clin Genet 53: 102-107.

12. Chan V, Chan VW, Yip B, Chim CS, Chan TK (1998) Haemophilia B in a female carrier due to skewed inactivation of the normal X-chromosome. Am J Hematol 58: $72-76$.

13. Aral B, de Saint Basile G, Al-Garawi S, Kamoun P, Ceballos-Picat I (1996) Novel nonsense mutation in the hypoxanthine guanine phosphoribosyltransferase gene and nonrandom X-inactivation causing Lesch-Nyhan syndrome in a female patient. Hum Mutat 7: 52-58.

14. Yorifuji T, Muroi J, Uematsu A, Tanaka K, Kiwaki K, Endo F, Matsuda I, Nagasaka H, Furusho K (1998) Xinactivation pattern in the liver of a manifesting female with ornithine transcarbamylase (OTC) deficiency. Clin Genet 54: 349-353.

15. Tanner SM, Orstavik KH, Kristiansen M, Lev D, Lerman-Sagie T, Sadeh M, Liechti-Gallati S (1999) Skewed X-inactivation in a manifesting carrier of $\mathrm{X}$ linked myotubular myopathy and in her non-manifesting carrier mother. Hum Genet 104: 249-253.

16. Redonnet-Vernhet I, Ploos van Amstel JK, Jansen RP, Wevers RA, Salvayre R, Levadew T (1996) Uneven X inactivation in a female monozygotic twin pair with Fabry disease and discordant expression of a novel mutation in the alpha-galactosidase A gene. $\mathrm{J} \mathrm{Med}$ Genet 33: 682-688. 
17. Aivado M, Gattermann N, Rong A, Giagounidis AAN, Prall WC, Czibere A, Hildebrandt B, Haas R, Bottomley SS (2006) X-linked sideroblastic anemia associated with a novel ALAS2 mutation and unfortunate skewed X-chromosome inactivation patterns. Blood Cells Mol Dis 37: 40-45.

18. Cau M, Addis M, Congiu R, Meloni C, Cao A, Santaniello S, Loi M, Emma F, Zuffardi O, Ciccone R, Sole G, Melis MA (2006) A locus for familial skewed $\mathrm{X}$ chromosome inactivation maps to chromosome $\mathrm{Xq} 25$ in a family with a female manifesting Lowe syndrome. J Hum Genet 51: 1030-1036.

19. Sharp A, Robinson D, Jacobs P (2000) Age- and tissuespecific variation of $\mathrm{X}$ chromosome inactivation ratios in normal women. Hum Genet 107: 343-349.
20. Sumita DR, Vainzof M, Campiotto S, Cerqueira AM, Canovas M, Otto PA, Passos-Bueno MR, Zatz M (1998) Absence of correlation between skewed X inactivation in blood and serum creatine-kinase levels in Duchenne/Becker female carriers. Am J Med Genet 80: 356-361.

21. Orstavik KH, Scheibel E, Ingerslev J, Schwartz M (2000) Absence of correlation between X chromosome inactivation pattern and plasma concentration of factor VIII and factor IX in carriers of haemophilia A and B. Thromb Haemost 83: 433-437.

22. Naumova AK, Plenge RM, Bird LM, Leppert M, Morgan K Willard HF, Sapienza C (1996) Heritability of $\mathrm{X}$ chromosome-inactivation phenotype in a large family. Am J Hum Genet 58: 1111-1119. 